\title{
Emotional Intelligence as Predictor of Mental Health among Normal and Chronic Disease Group
}

\author{
Renu Sodhi ${ }^{1 *}$
}

\section{ABSTRACT}

The current study investigates the impact of emotional intelligence on mental health among normal healthy individuals and chronic disease group. This study is based on primary as well as secondary data that has been collected from the various sources. Sample size of the study is 400 respondents (200 normal healthy individuals, 200 chronic disease group individuals). Multidimensional Measure of Emotional Intelligence (MMEI) and General Health Questionnaire (GHQ) were used for the purpose of data collection. In statistical tools Pearson Product Moment Correlation and Step-Wise Multiple Regression has been applied. The major findings of the study shows that various factors of emotional intelligence is significantly associated with mental health and further Step-wise multiple regression analysis revealed that emotional intelligence is significant predictor of mental health.

Keywords: Emotional Intelligence; Mental Health; Normal Healthy Individuals; Chronic Diseases Group

Emotional Intelligence is a set of skills, attitudes, abilities and competencies that determine the individual's behavior, reactions, state of mind, coping style and communication style. These factors directly affect the level of success satisfaction, ability to cope with stress, level of self esteem, perception of control and overall level of mental and emotional well being.

Goleman (1995) made a provocative claim that it Intelligence Quotient contribution up to 25\% to life's success, the remaining was fulfilled through one's emotional intelligence and as a result predicted "Emotional Intelligence would contribute to the success at home, at school and at work.” Mayer and Salovey (1990) defined emotional intelligence as “the ability to monitor one's own and others' feelings and emotions, to discriminate among them and to use this information to guide one's thinking and actions." According to Bar-on (1997) "emotional intelligence reflects one's ability to deal with daily environment challenges and helps predict one's success in life,

\footnotetext{
${ }^{1}$ Research Scholar, Department of Applied Psychology, Guru Jambheshwar University of Science \& Technology, Hisar-Haryana. India *Responding Author

(C) 2016 Sodhi R; licensee IJIP. This is an Open Access Research distributed under the terms of the Creative Commons Attribution License (http://creativecommons.org/licenses/by/2.0), which permits unrestricted use, distribution, and reproduction in any Medium, provided the original work is properly cited.
} 


\section{Emotional Intelligence as Predictor of Mental Health among Normal and Chronic Disease Group}

including professional and personal pursuits.” Salovey and Mayer (1997) described emotional intelligence as "The ability to perceive appraise, and express emotion accurately and adaptively: the ability to understand emotion and emotional knowledge; the ability to access and or generate feelings when they facilitate thought; and the ability to regulate emotions in ways that assist thought”.

EH (Emotional health) is the language of the state of Mental Health (MH) at affective domains. Through EH one expresses and understands the feelings of others and self and manages them constructively. EI also helps in directing strong feelings like love/hate towards inner being. It contains destructive feelings by using positive feelings like love, anger constructively and demonstrates the ability to laugh, relate and enjoy. Some forms of EI may protect people from stress and lead to better adaptation. For example, an objective measure of emotion management skill has been associated with a tendency to maintain an experimentally induced positive mood (Ciarrochi et al., 2000). EI is related with lower level of stress and reduced chance of its adverse consequences (Pau \& Croucher, 2003; Duran \& Ray, 2004; Hunt \& Evans, 2004; Naidoo \& Pau, 2008).

Individuals who can regulate their emotions are healthier because they _accurately perceive and appraise their emotional states, know how and when to express their feelings, and can effectively regulate their mood states'. This set of characteristics, dealing with the perception, expression, and regulation of moods and emotions, suggests that there must be a direct link between EI and physical as well as psychological health (Salovey, Bedell, Detweiler \& Mayer, 1999). An emotionally intelligent person can cope better with life's challenges and control their emotions more effectively, both of which contribute to good psychological and physical health (Taylor, 2001). There is a relationship between EI, stress and a number of measures of psychological health, such as depression, hopelessness and suicidal ideation among young people (Ciarrochi, Deane \& Anderson, 2002).

The adaptive perception of emotion, use of emotion to enhance cognition, understanding of emotion, and regulation of emotion may contribute to mental and physical health in various ways. The level of emotional intelligence may have implications for both mental disorders in which emotion plays a central role as well as disorders that relate to non-emotional features of emotional intelligence.

\section{LITERATURE REVIEW}

Kedrnath (2003) studied mental health, emotional maturity, emotional intelligence and selfacceptance among 100 participants with the age range of 19-22 years. Major findings of the study indicated that mental health has significant positive correlation with the emotional maturity, emotional intelligence and self-acceptance. The results of the path analysis further 


\section{Emotional Intelligence as Predictor of Mental Health among Normal and Chronic Disease Group}

revealed that the mental health and emotional maturity enhance the self-acceptance through the emotional intelligence of the participants.

Tsaousis and Nikolaou (2005) investigated the relationship of emotional intelligence (EI) characteristics, such as perception, control, use and understanding of emotions, with physical and psychological health. The findings revealed that there is a relationship between emotional intelligence and health functioning, and hierarchical regression analyses indicated the unique contribution of each of the emotional intelligence scales on the overall health score.

Schutte et al. (2006) conducted a meta-analysis of 44 effect sizes based on the responses of 7,898 participants. They found that higher emotional intelligence was associated with better health. Emotional intelligence had a weighted average association with mental health, psychosomatic health, and physical health. The findings provide a basis for research aimed at determining the causal relationship between trait emotional intelligence and health.

Salguero et al. (2011) analyzed the predictive validity of perceived emotional intelligence (attention to feelings, emotional clarity, and emotional repair) over psychological adjustment in an adolescent sample at two temporal stages with 1-year interval. The findings suggest that perceived emotional intelligence is a stable predictor of adolescent adjustment and may serve as a useful resource for preventive interventions.

Kong et al. (2012) studied the positive and negative affect on the association between trait emotional intelligence and mental distress on a sample of 726 Chinese adults (384 females) with an age range of 18-60 years. Hierarchical regression analysis showed that EI was a significant predictor of positive affect, negative affect and mental distress. Further mediation analysis revealed that positive and negative affect acted as partial mediators of the relationship between emotional intelligence and mental distress. This result indicated that positive affect and negative affect played an equally important function in the association between EI and distress.

The above historical background prove that emotional intelligence enhance the ability to monitor one's own and other's feelings and emotions and has a positive impact on psychological as well as physical health functioning.

\section{Objectives of the study}

1. To ascertain the association between dimensions of Emotional intelligence and mental health among chronic disease group.

2. To ascertain the association between dimensions of Emotional intelligence and mental health among normal healthy group.

3. To study the role of Emotional Intelligence in predicting mental health. 
Emotional Intelligence as Predictor of Mental Health among Normal and Chronic Disease Group

\section{Hypotheses of the study}

1. Different dimensions of Emotional Intelligence would be positively correlated with mental health among chronic disease group.

2. Different dimensions of Emotional Intelligence would be positively correlated with mental health among normal healthy group.

3. Emotional Intelligence would be significant predictor of mental health.

\section{METHODS}

\section{Sample}

The sample of the present study consisted of 400 individuals of both sexes of age 40 to 60 years with mean age of 48.63 years. Out of these 200 were chronic patients and 200 were normal healthy individuals. Already diagnosed patients by the physicians were included in chronic disease group. Mainly the persons in chronic disease group included patients of chronic heart disease, hypertension, diabetes, asthma, cancer, and tuberculosis. The control group comprised of normal healthy individuals who maintain good health. Special care has been taken to ascertain that healthy respondents had not undergone any type of major disease during last 5 years.

\section{Tools}

The following instruments were used for the purpose of data collection in the present study:

\section{Multidimensional Measure of Emotional Intelligence (MMEI)}

Multidimensional Measure of Emotional Intelligence (MMEI) scale given by C. R. Darolia (2003) was used. The MMEI is comprised of 80 multiple choice items distributed in five dimensions, each consisting of 16 items. Each item is answered on a five-point scale. The subdimensions are listed as follows: self-awareness, managing emotions, motivating-oneself, empathy and handling relationships. It is widely used scale to measure the emotional intelligence and its related aspects. The test retest coefficient of the test ranged between 0.79 to 0.84 . The validity of the scale is 0.78 .

\section{General Health Questionnaire (GHQ)}

GHQ is given by David Goldberg and Paul Williams (1988). This scale measures mental health of the individual. The shorter version of GHQ-30 is used in the present study. The split-half reliability coefficient of GHQ-30 is .92 and test-retest reliability is .77. Specificity (\%) is 87.0 and Sensitivity (\%) is 91.4 .

\section{Statistical Analysis}

As per the objectives the following statistical tools were used:

- $\quad$ Pearson Product Moment Correlation and Step-Wise Multiple Regression that are calculated with the help of SPSS $\left(16^{\text {th }}\right.$ version). 


\section{RESULTS}

The coefficients of correlations were computed to study the associations between 5 factors of emotional intelligence and the measure of mental health. Intercorrelation was followed by multiple regression. The Intercorrelation of chronic disease group is reported in Table 1 and the Intercorrelation of normal healthy group is presented in Table 2. The description of correlations among different measures is presented under the following separate headings:

Table 1, Inter-Correlation Matrix of Chronic Diseases Group (N-200)

\begin{tabular}{|l|l|l|l|l|l|l|}
\hline Variable & SA & ME & MO & E & HR & MH \\
\hline SA & 1 & & & & & \\
\hline ME & $.42^{* *}$ & 1 & & & & \\
\hline MO & $.22^{* *}$ & $.45^{* *}$ & 1 & & & \\
\hline E & .09 & .02 & .06 & 1 & & \\
\hline HR & $.17^{*}$ & $.42^{* *}$ & $.52^{* *}$ & .02 & 1 & \\
\hline MH & .04 & $-.27^{* *}$ & $-.44^{* *}$ & $.21^{* *}$ & $-.55^{* *}$ & 1 \\
\hline
\end{tabular}

$* * \mathrm{p}<.01,{ }^{*} \mathrm{p}<.05$

Table 2, Inter-Correlation Matrix of Normal Healthy Group (N-200)

\begin{tabular}{|l|l|l|l|l|l|l|}
\hline Variable & SA & ME & MO & E & HR & MH \\
\hline SA & 1 & & & & & \\
\hline ME & $.41^{* *}$ & 1 & & & & \\
\hline MO & $.27^{* *}$ & $.43^{* *}$ & 1 & & & \\
\hline E & -.06 & .11 & $.26^{* *}$ & 1 & & \\
\hline HR & $.28^{* *}$ & $.46^{* *}$ & $.32^{* *}$ & .06 & 1 & \\
\hline MH & $-.28^{* *}$ & $-.44^{* *}$ & $-.49^{* *}$ & $-.15^{*}$ & $-.36^{* *}$ & 1 \\
\hline
\end{tabular}

${ }^{* *} \mathrm{p}<.01,{ }^{*} \mathrm{p}<.05$

Intercorrelations between the dimensions of emotional intelligence and mental health among chronic disease group

The findings mentioned in Table 1 (Intercorrelation matrix) describe the relationship between emotional intelligence and mental health among chronic disease group. The Table 1 reveals that the measure of mental health is significantly correlated with four factors of emotional intelligence out of total five factors. Self-awareness, the first measure of emotional intelligence has no significant correlation with the measure of mental health for the total sample of chronic disease group.

Managing emotions, the second measure of emotional intelligence is significantly negatively correlated with the measure of mental health ( $\mathrm{r}=-.27, \mathrm{p}<.01)$ (Table 1).

The third measure of emotional intelligence motivating oneself $(r=-.44, p<.01)$ is significantly negatively correlated with the measure of mental health (Table 1).

(C) The International Journal of Indian Psychology, ISSN 2348-5396 (e) | ISSN: 2349-3429 (p) | 133 
Empathy, the fourth measure of emotional intelligence is positively correlated with the measure of mental health $(\mathrm{r}=.21, \mathrm{p}<.01)$ (Table 1$)$.

Handling relationships, the fifth measure of emotional intelligence $(r=-.55, \mathrm{p}<.01)$ is also significantly negatively correlated with the measure of mental health among chronic disease group (here negative correlation implies the positive relationship due to the scoring procedure of the measure of mental health) (Table 1).

Intercorrelations between the dimensions of emotional intelligence and mental health among normal healthy group

A review of Intercorrelation matrix as shown in Table 2 describes the relationship between emotional intelligence and mental health among normal healthy group. The Table 4.18 reveals that the measure of mental health is significantly correlated with all the factors of emotional intelligence. It has been observed that self awareness, the first measure of emotional intelligence is significantly negatively correlated with the measure of mental health $(\mathrm{r}=-.28, \mathrm{p}<.01)$.

Managing emotions, the second measure of emotional intelligence is also significantly and negatively correlated with the measure of mental health $(\mathrm{r}=-.44, \mathrm{p}<.01)$ (Table 2$)$.

Motivating oneself, the third measure of emotional intelligence is also significantly negatively correlated $(\mathrm{r}=-.49, \mathrm{p}<.01)$ with the measure of mental health (Table 2$)$.

Empathy, the fourth measure of emotional intelligence is also significantly negatively correlated $(\mathrm{r}=-.15, \mathrm{p}<.01)$ with the measure of mental health (Table 2).

Handling relationships, the fifth measure of emotional intelligence is also significantly negatively correlated $(\mathrm{r}=-.36, \mathrm{p}<.01$ ) with the measure of mental health for the sample of normal healthy group (Table 2).

\section{Regression Analysis}

Regression analysis was conducted to identify the specific determinants of mental health in normal and chronic diseases group separately. For this purpose method of stepwise multiple regression was used. The results are depicted in Tables 3 and 4.

Table 3, Multiple $R$ and $R^{2}$ change for mental health in chronic diseases group (as a consequence of step-wise regression equation)

\begin{tabular}{|l|l|l|l|l|l|l|l|}
\hline Predictor & $\mathbf{R}^{2}$ & $\begin{array}{l}\mathbf{R}^{2} \\
\text { Change }\end{array}$ & $\boldsymbol{\beta}$ & SE & $\mathbf{B}$ & $\mathbf{t}$-value & Sig. \\
\hline Constant & & & 44.84 & 5.91 & & 7.59 & .00 \\
\hline $\begin{array}{l}\text { EI (Handling } \\
\text { relationships) }\end{array}$ & .300 & .300 & -.43 & .08 & -.33 & 5.41 & .00 \\
\hline $\begin{array}{l}\text { EI (Motivating } \\
\text { oneself) }\end{array}$ & .400 & .037 & -.30 & .08 & -.24 & 3.99 & .00 \\
\hline EI (Empathy) & .434 & .034 & .26 & .08 & .17 & 3.18 & .00 \\
\hline
\end{tabular}

$* * \mathrm{p}<.01, * \mathrm{p}<.05$ 


\section{Emotional Intelligence as Predictor of Mental Health among Normal and Chronic Disease Group}

Findings mentioned in Table no. 3 indicate that the variable of handling relationships (a sub variable of emotional intelligence), realistic acceptance (a sub variable of spirituality), motivating oneself, and empathy (sub variables of emotional intelligence), met the criterion to enter in the regression equation and explained $43 \%$ of variance for mental health among the group of chronic disease. It indicated that all these variables are predictors of mental health.

The first variable that is handling relationships (a sub variable of emotional intelligence) entered in regression equation with $\mathrm{R}^{2} 0.300(\mathrm{~F}=85.03, \mathrm{p}<.01)$, and $\mathrm{b}$-value is -0.33 , which is significant at .01 level, which means that handling relationships accounted for $30 \%$ of variance in criterion variable i.e. mental health (Table 3).

The second variable motivating oneself (a sub variable of emotional intelligence) entered in the regression equation with $\mathrm{R}^{2} 0.400(\mathrm{~F}=43.53, \mathrm{p}<.01)$, and $\mathrm{b}$-value is -0.24 , which is significant at .01 level, which implies that motivating oneself accounted for $40 \%$ of variance in the criterion variable together with handling relationships and realistic acceptance and only $4 \%$ of variance, when taken alone (Table 3).

The results presented in Table 4.03 further revealed that at the third and last step empathy (a sub variable of emotional intelligence) entered in the regression equation with $R^{2} 0.434$ ( $F=37.33$, $\mathrm{p}<.01$ ), and b-value is 0.17 , which is significant at .01 level. This implies that empathy together with other predictors (i.e. handling relationships, realistic acceptance and motivating oneself) explains $43 \%$ of variance in the criterion variable, whereas at its own level it contributes only $3 \%$ of variance.

Table 4, Multiple $R$ and $R^{2}$ change for mental health in normal healthy group (as a consequence of step-wise regression equation)

\begin{tabular}{|l|l|l|l|l|l|l|l|}
\hline Predictor & $\mathbf{R}^{2}$ & $\begin{array}{l}\mathbf{R}^{2} \\
\text { Change }\end{array}$ & $\boldsymbol{\beta}$ & SE & $\mathbf{b}$ & t-value & Sig. \\
\hline Constant & & & 22.86 & 3.94 & & 5.80 & .00 \\
\hline $\begin{array}{l}\text { EI (Motivating } \\
\text { oneself) }\end{array}$ & .367 & .119 & -.27 & .05 & -.32 & 5.22 & .00 \\
\hline
\end{tabular}

${ }^{* *} \mathrm{p}<.01,{ }^{*} \mathrm{p}<.05$

The regression analysis on mental health in normal healthy group revealed that one predictor met the criterion to enter in the regression equation. As reflected in Table 4 motivating oneself (a sub variable of emotional intelligence), explained $37 \%$ of variance for mental health among normal healthy group. It indicated that this variable is predictor of mental health.

Result presented in Table 4 reveals that the variable motivating oneself (a sub variable of emotional intelligence) entered in regression equation with $\mathrm{R}^{2} 0.367(\mathrm{~F}=57.01, \mathrm{p}<.01)$, and b-

(c) The International Journal of Indian Psychology, ISSN 2348-5396 (e)| ISSN: 2349-3429 (p) | 135 


\section{Emotional Intelligence as Predictor of Mental Health among Normal and Chronic Disease Group}

value is -0.32 , which is significant at .01 level. This implies that motivating oneself explains $37 \%$ of variance in the criterion variable jointly with disappointment and if considered alone accounts for only $12 \%$ of variance.

\section{DISCUSSION}

The results presented in Table 1 revealed that the negative correlation of the different measures of emotional intelligence namely managing emotions, motivation oneself and handling relationship with the measure of mental health implies the positive relationship between them because of reverse scoring of the measure of mental health. It clearly means that managing emotions, motivation oneself and skills of handling relationships has been related with better mental health. The positive correlation between empathy (a dimension of emotional intelligence) and the measure of mental health implies the negative association between them, which means that over sensitivity to other' feelings, concerns, and taking their perspective lead to poor mental health. On the basis of these findings the first hypothesis that states "Different dimensions of emotional intelligence would be positively correlated with mental health among chronic disease group” got accepted.

The results presented in Table 2 revealed that the negative correlation between the dimensions of emotional intelligence (self awareness, managing emotions, motivation oneself, empathy and handling relationships) with the measure of mental health implies the positive association between them. It means that awareness about self, the skills of handling emotions, emotional self control, sensitivity about other's feelings would be related to better mental health. On the basis of these findings the second hypothesis that states, "Different dimensions of emotional intelligence would be positively correlated with mental health among normal healthy group” got accepted.

Earlier studies and results of the present study are in accordance with the fact that emotional intelligence is significantly associated with better mental and physical health. Matthews et al. (2002) found that lack of awareness of emotion and inability to manage emotions are key symptoms in some personality disorders and impulse control disorders. Supporting a link between lower emotional intelligence and lack of awareness of emotional processes as well as impulse control problems, Schutte et al. (1998) found that lower emotional intelligence is associated with more alexithymia and less impulse control. Higher emotional intelligence is linked with aspects of better psychosocial functioning, including intrapersonal factors such as greater optimism and interpersonal factors such as better social relationships (e.g., Brown \& Schutte, 2006; Salovey \& Grewal, 2005; Schutte et al., 2001; Schutte et al., 1998).

Ciarrochi et al. (2002) suggested that emotional Intelligence is a distinctive construct as well as being important in understanding the link between stress and mental health. Extremera and Fernandez-Berrocal (2002) provide empirical evidence that aspects of perceived emotional 


\section{Emotional Intelligence as Predictor of Mental Health among Normal and Chronic Disease Group}

intelligence may account for the health-related quality of life in midlife including social, physical and psychological symptoms. Extremera and Berrocal (2006) showed that high emotional attention was positively and significantly related to high anxiety, depression and to low levels of role emotional, social functioning, and mental health. However, high levels of emotional clarity and mood repair were related to low levels of anxiety and depression, high role physical, social functioning, mental health, vitality and general health. Choubey et al. (2009) also revealed that emotional intelligence and its various component abilities are associated with better health outcomes and lower levels of stress.

Results presented in Table 3 revealed that the regression coefficients ' $b$ ' of handling relationships (a sub variable of emotional intelligence) and motivating oneself (a sub variable of emotional intelligence) indicate that the direction of influence was negative, except for empathy (a sub variable of emotional intelligence), where it was positive. The ' $b$ ' coefficients clearly reveal that handling relationships and motivating oneself are making positive contribution towards mental health (higher score on mental health indicates poor mental health), whereas one dimension of emotional intelligence i.e. empathy, making negative contribution towards mental health. The later finding seems to be need of replication in the context of one variable involved.

A review of Table 4 revealed that the regression coefficients ' $b$ ' of motivating oneself (sub variables of emotional intelligence) indicate that the direction of influence was negative. The ' $b$ ' coefficients clearly reveal that motivating oneself, is making positive contribution towards mental health (higher score on mental health indicates poor mental health).

Similar findings come from Kedrnath (2003) who studied mental health, emotional maturity, emotional intelligence and self-acceptance and indicated that mental health has significant positively correlated with the emotional maturity, emotional intelligence and self-acceptance. The results of the path analysis further revealed that the mental health and emotional maturity enhance the self-acceptance through the emotional intelligence of the participants.

Schutte et al. (2006) conducted a meta-analysis and found that higher emotional intelligence was associated with better health. Naidoo and Pau (2008) studied the role of emotional intelligence (EI) plays in the experience of perceived stress (PS) and indicated a statistically significant inverse relationship between EI and PS. Stepwise regression analysis identified EI as the significant predictors of PS. The $t$ statistic also indicated that EI is relatively the most important predictor of PS.

It can be inferred from the results that the variables related emotional intelligence were influential predictors of mental health among chronic and normal healthy individuals. Hence, the hypothesis that states "Emotional Intelligence would be significant predictor of mental health" got accepted. 


\section{CONCLUSION}

In the last it can be concluded that various factors of emotional intelligence is significantly associated with positive mental health and also a better predictor of mental health. Thus individuals with high level of emotional intelligence possess good mental health. So, one can enhance one's positive health by improving positive emotions and positive attitude towards life.

\section{Acknowledgments}

The author appreciates all those who participated in the study and helped to facilitate the research process.

\section{Conflict of Interests}

The author declared no conflict of interests.

\section{REFERENCES}

Bar-On, R. (1997). The Emotional Quotient Inventory (EQi): Technical manual. Toronto: MultiHealth Systems, Inc.

Brown, R. F., \& Schutte, N. S. (2006). Direct and indirect relationships between emotional intelligence and subjective fatigue in university students. Journal of Psychosomatic Research, 60, 585-593.

Ciarrochi, J., Chan, A., \& Caputi, P. (2000). A critical evaluation of the emotional intelligence construct. Personality and Individual Difference, 28, 539-561.

http://www.researchgate.net/publication/45514664_A_critical_evaluation_of_the_emotio nal_intelligence_construct/file/d912f505b18f02a0f1.pdf

Ciarrochi, J., Deane, F. P., \& Anderson, S. (2002). Emotional intelligence moderates the relationship between stress and mental health. Journal of Personality and individual differences, 32(2), 197-209.

Choubey, A. K., Singh, S. K., \& Pandey, R. (2009). Role of Emotional Intelligence in Stress and Health. Indian Journal of Social Science Researches, 6(1), 122-134. http://ijssr.110mb.com/IJSSR-March-2009-vol-6.pdf\#page=125

Darolia, C. R. (2003). Manual for Multidimensional Measures of Emotional Intelligence. Jagsons India, 6 M C Market, Ambala Cantt.-33001. India.

Duran, A. N., \& Ray, L. (2004). Self-report emotional intelligence, burnout and engagement among staff in service for people with intellectual disabilities. Psychological Reports, 95, 452-575.

Extremera, N., \& Berrocal, P. F. (2006). Emotional intelligence as predictor of mental, physical and social health in university students. The Spanish Journal of Psychology, 9(1), 45-51.

Extremera, N., \& Fernandez-Berrocal, P. (2002). Relation of perceived emotional intelligence and health-related quality of life of middle-aged women. Psychological Reports, 91(1), 47-59. 


\section{Emotional Intelligence as Predictor of Mental Health among Normal and Chronic Disease Group}

Goldberg, D., \& Williams, P. (1988). Manual for General Health Questionnaire. The Basingstoke Press Limited, Basingstoke, Hampshire.

Goleman, D., (1995). Emotional Intelligence, New York: A Bantam Book.

Hunt, N., \& Evans, D. (2004). Predicting traumatic stress using emotional intelligence. Behavior Research and Therapy, 42, 791-798.

http://www.academia.edu/189502/Predicting_traumatic_stress_using_emotional_intelligence

Kedrnath, B. J. (2003). The Mental health, emotional maturity, emotional intelligence and selfacceptance. M.Phil. unpublished dissertation. Acharya Nagarjuna University.

Kong, F., Zhao, J., \& You, X. (2012). Trait emotional intelligence and mental distress: The mediating role of positive and negative affect. International Journal of Psychology, 47 (6), 460-466. http://dx.doi.org/10.1080/00207594.2012.666352

Mayer, J. D., \& Salovey, P. (1997). What is emotional intelligence? In P. Salovey \& D. J. Sluyter (Eds.), Emotional Development and Emotional Intelligence: Educational Implications (pp. 3-31). Basic Books: New York.

Matthews, G., Zeidner, M., \& Roberts, R. D. (2002). Emotional intelligence: science and myth. Cambridge, MA: MIT Press.

Naidoo, S., \& Pau, A. (2008). Emotional intelligence and perceived stress. Journal of the South African Dental Association, 63(3), 148-151.

Pau, A. K., \& Croucher, R. (2003). Emotional intelligence and perceived stress in dental undergraduates. Journal of Dental Education, 67(9), 1023-1028.

http://www.jdentaled.org/content/67/9/1023.full.pdf+html

Salguero, J. M., Palomera, R., \& Fernández-Berrocal, P. (2011). Perceived emotional intelligence as predictor of psychological adjustment in adolescents: a 1-year prospective study. European Journal Psychology Education, Published online: 04 May, 2011.

Salovey, P., \& Grewal, D. (2005). The science of emotional intelligence. Current Directions in Psychological Science, 14(6), 281-285.

Salovey, P., Bedell, B. T., Detweiler, J. B., \& Mayer, J. D. (1999). Coping intelligently: Emotional intelligence and the coping process. In C.R. Snyder (Ed.), Coping: The psychology of what works (pp. 141-164). New York: Oxford Psychology Press.

Schutte, N. S., Malouff, J. M., Hall, L. E., Haggerty, D. J., Cooper, J. T., Golden, C. J., et al. (1998). Development and validation of a measure of emotional intelligence. Personality and Individual Differences, 25, 167-177.

Schutte, N. S., Malouff, J. M., Bobik, C., Conston, T., Greeson, C., Jedlicka, C., et al. (2001). Emotional intelligence and interpersonal relations. Journal of Social Psychology, 141(4), 523-536. http://www.tandfonline.com/doi/pdf/10.1080/00224540109600569

Schutte, N. S., Malouff, J. M., Thorsteinsson, E. B., Bhullar, N., \& Rooke, S. E. (2006). A metaanalytic investigation of the relationship between emotional intelligence and health. Personality and Individual Differences, 42(6), 921-933.

http://www.sciencedirect.com/science/article/pii/S0191886906003539 
Tsaousis, I., \& Nikolaou, I. (2005). Exploring the relationship of emotional intelligence with physical and psychological heath functioning. Journal of Stress and Health, 21(2), 77-86. http://onlinelibrary.wiley.com/doi/10.1002/smi.1042/pdf

How to cite this article: Sodhi R (2016), Emotional Intelligence as Predictor of Mental Health among Normal and Chronic Disease Group, International Journal of Indian Psychology, Volume 4, Issue 1, No. 80, ISSN:2348-5396 (e), ISSN:2349-3429 (p), DIP:18.01.114/20160401, ISBN:978-1-365-57867-0 